\title{
Assessing changes in travel behavior induced by modified travel times A stated adaptation survey and modeling approach
}

\author{
Journal Article \\ Author(s): \\ Weis, Claude; Axhausen, Kay W. (10) \\ Publication date: \\ 2012 \\ Permanent link: \\ https://doi.org/10.3929/ethz-b-000163435 \\ Rights / license: \\ In Copyright - Non-Commercial Use Permitted \\ Originally published in: \\ disP - The Planning Review 48(3), https://doi.org/10.1080/02513625.2012.759347
}




\title{
Assessing changes in travel behaviour induced by modified travel times A stated adaptation survey and modelling approach
}

\author{
Claude Weis \\ Research assistant / PhD student in Transport Planning \\ Institute for Transport Planning and Systems (IVT), ETH Zurich \\ HIL F 33.1, ETH Hönggerberg \\ Wolfgang-Pauli-Str. 15 \\ $\mathrm{CH}-8093$ Zurich \\ Switzerland \\ Phone: +41-44-633 3952 \\ Fax: +41-44-633 1057 \\ Email: weis@ivt.baug.ethz.ch \\ Kay W. Axhausen \\ Professor in Transport Planning \\ Institute for Transport Planning and Systems (IVT), ETH Zurich \\ HIL F 32.3, ETH Hönggerberg \\ Wolfgang-Pauli-Str. 15 \\ $\mathrm{CH}-8093$ Zurich \\ Switzerland \\ Phone: +41-44-633 3943 \\ Fax: +41-44-633 1057 \\ Email: axhausen@ivt.baug.ethz.ch
}

\section{Abstract}

The paper reports on research exploring a stated adaptation approach for analyzing changes in travel behaviour brought about by changes in generalised costs of travel. A sample of respondents returned a five-day travel diary, from which one day was selected for further analysis. The conditions of the reported day were modified using predefined heuristics, to attain significant changes in the generalised costs of the reported trips. The respondents were then faced with these hypothetical scenarios in face-to-face interviews, and asked to state how the implied changes would have affected their activity scheduling on the specified day and to adapt their reported schedule.

The data was used to estimate models of scheduling adaptations. A series of models was used to assess the adaptations stated by the respondents. At the core is a Multiple Discrete-Continuous Extreme Value (MDCEV) model, which is used to predict how the gained or lost time is compensated by the respondents.

The adaptations to the respondents' schedule were surprisingly sparse despite the substantial changes in generalized costs imposed by the scenarios. The most frequent adaptations were changes in departure time from the home location, and mode or destination changes to recover the lost time. The expected changes, concerning the number of conducted trips and activities and their combination into home-to-home tours, were extremely rare. Respondents are very selective when making adaptations to their routine, even under extreme circumstances.

The paper describes the survey approach, which to our best knowledge is novel in its application, reports model results of the respondents' reactions to the changes implied in the household interviews, and provides an example application of the results. 


\section{Introduction and Motivation}

In a broad context, induced traffic can be defined as changing demand for transport services generated by changing travel conditions, resulting in different generalised costs of participating in out-of-home activities. The main focus of past studies of the phenomenon has often been the analysis of specific and localized measures bringing about such changes, such as the construction of new roads or rail lines in given corridors, and the assessment of side effects of those measures. The research described in this paper takes a more general approach and deals with the effects of changing generalised costs of travel on traffic generation: the propensity of participating in out-ofhome activities, the time spent at those activities, the resulting number of trips and activities conducted, the chaining of those trips and activities into tours (sequences of trips and activities starting and ending at the home location), as well as their timing.

In the context of the classical four-step model of transportation system planning, the main focus of the research is thus on activity and trip generation, with changes in destination choice being considered a consequence of re-calibrating the time budget to compensate travel time changes. Mode choice is covered as a side effect of the same time budget re-allocation, while route choice is left out altogether, as the study lacks the necessary geographic detail.

The work described here is part of a research project funded by the Swiss Association of Transportation Engineers (SVI). In a first analysis (described in Weis 2009; Weis, Axhausen 2009), the effects of historically changing accessibility values (at the municipal level) on the abovementioned mobility indicators were assessed with a pseudo-panel based structural equations model. The second part, which is described here, aims at assessing the abovementioned effects on a short-term, disaggregate scale.

Stated preference (SP) data have, often in combination with revealed preference (RP) data, found widespread application in travel demand models. The combination of RP and SP data sources is the state of practice in most such models. In Switzerland, the Microcensus (national household travel survey) is the main RP data source for the national person transport model, while specialized SP surveys have been conducted for the assessment of specific policies, e.g. the introduction of road pricing schemes (Vrtic et al. 2010) or tilting trains (Vrtic, Axhausen 2003). In compliance with the state-of-the-art (Rose et al. 2008), SP surveys should be constructed based on reported behaviour, in order to maximise the recognisability of the choice situations for the respondents. However, such approaches are almost exclusively limited to trip-based models (i.e., one reported trip is modified when constructing the SP experiments), while activity-based approaches have often neglected the SP component. The study attempts to introduce SP data into an activity-based modelling approach. The base of the research is a stated adaptation survey that picks up on the tradition of the Household Activity Travel Simulator, or HATS (Jones 1979).

The paper describes the survey approach, which to our best knowledge is novel in its application, and reports the model results of the respondents' reactions to the changes implied in the household interviews.

\section{Literature Review}

When assessing the outcome of demand management policies on individuals' and households' travel behaviour, it is important to understand the underlying decision making process. A convenient means of recording such decisions are stated response surveys (Louvière et al. 2000). In transport research, such surveys are often implemented as stated choice experiments, where respondents are faced with a destination, mode, route or departure time choice situation where the attributes of several pre-determined alternatives are varied. Such experiments, which are limited to a single trip, rarely include a trip generation component. Thus the respondents are generally not given the choice of either not travelling or re-arranging their trip sequence in order to accommodate their needs. However, travel decisions are generally made in a medium to long rather than a short term 
perspective, and trip and activity sequences are scheduled not on-the-fly, but rather on a daily or even weekly basis. Thus it seems important to model the decision processes and in consequence also to conduct the underlying choice experiments in a context that can appropriately account for the complex scheduling process. An early attempt to conduct such experiments was the Household Activity Travel Simulator, or HATS (Jones 1979). The approach consists of a two-stage methodology where households are first asked to report their existing behaviour for a certain period of time (that is, to complete a travel diary), based on which the choice experiments are then constructed. For the HATS interview, the setting for the household is modified by a hypothetical policy or other changes inducing a change to one or more generalised cost components, and the respondents are asked to adapt their schedules to the new situation. The survey tool used for these interviews consisted of a game-like display board, on which the respondents could visualize and test their adaptations. The approach thus ensures that the implications for all relevant decisions (activity and trip generation, scheduling and chaining; destination, mode and route choice) can be captured according to modeling needs. The recorded reactions to the scenarios relate to the whole schedule rather than to a specific trip, as is often the case in traditional stated choice surveys. At the end of the interview, the researcher has a set of "before and after" reported schedules at their disposal. The methodology combines the advantage of modeling entire days (as opposed to single trips or journeys, as is the case in the traditional four-step transport models) with the possibility to capture reactions to changes. The latter dynamic effects cannot be captured in revealed preference settings (that is, the use of diary data alone), which are often used as data sources for transport models. The research described here uses an approach similar to the HATS, but is based on computer software, which facilitates the data management process.

As has been mentioned, applications of the HATS approach or similar methods in the literature are quite sparse. However, a few successful early examples can be found.

Jones (1980) describes various early applications of his approach, including changes to rail and bus services in the UK (Martin and Vorhees Associates 1978; Jones, Dix 1979; Brown, Mawson 1981). Jones et al. (1989) developed the Computerised Activity-Based Stated Preference (CASP) package; the field application that they describe is based on (hypothetically) forcing respondents to travel to work by public transport instead of car, and eliciting their reactions to such a constraint. The Adelaide Travel and Activity Questioner (ATAQ) described in the same paper faces households with parking pricing policies.

The studies described in Van Knippenberg-den Brinker, Clarke (1984) and Van Knippenberg-den Brinker, Lameijer (1985) examine the effects of bus service reductions with pre-determined schedules from which the respondents have to choose. They recognize the need to analyze the behaviour of all household members jointly, as well as to consider all activities, not just those that give rise to the journeys affected by the policy measure.

Phifer et al. (1980) describe an interactive technique called Response to Energy and Activity Constraints on Travel (REACT), which was tested with 12 households in the Albany, New York, area. They recognize that households often counteract travel constraints by modifying non-travel activities, a concept that is picked up in the present study.

The works by Lee-Gosselin $(1989,1990)$ apply a methodology similar to the HATS, referred to as the Car-Use Patterns Interview-Game (CUPIG). 45 households were interviewed about their probable car use under various fuel shortage scenarios. The studies described in Doherty, Lee-Gosselin (2000) and Doherty et al. (2002) apply the so-called CHASE (Computerized Household Activity Scheduling Elicitor) framework, to capture the effects of automobile use reduction scenarios. The three households that were interviewed while testing the approach stated a substantial amount of rescheduling decisions, mainly the adaptation of activity (respectively trip) start and end times as well as mode choice decisions (the latter likely being caused to a certain extent by the specific formulation of the experiment). The same software program was used for the study described in Doherty, Miller (2000), where respondents' planned schedules were recorded in advance and could then be modified onthe-fly as unexpected changes occurred in the real world. It is argued that many adaptations to 
schedules are made at a very short notice, and that the in situ nature of the tool allows to capture those changes very effectively. The approach that is described here is different in that it deals with stated preferences rather than capturing reactions to real changes in a revealed preference framework.

An internet based stated adaptation survey based on congestion pricing scenarios is described in Arentze et al. (2004). The authors employ an activity based approach, in which various facets of the activity scheduling process can be changed by the respondents. Their survey is different from ours in that a discrete set of options is offered for the adaptation process, rather than the complete restructuring of a reported activity pattern that we aim to capture.

\section{Implementation of the Survey}

The survey, which is described in more detail in Weis et al. (2010), consists of a three-stage approach where a random sample of respondents was first recruited for participation by telephone. RP data were collected from the respondents, based on which the SP part of the survey was then constructed. A travel diary similar to the multi-day trip based MobiDrive questionnaires that had previously been used in Switzerland (Löchl et al. 2005; Axhausen et al. 2002) was dispatched to the respondents. An analogous questionnaire was programmed with an internet based interface, for which each participating household received a user name and password and was assigned a period of five days over which to record their travel. Participants were given the choice between the online and a traditional pen-and-paper diary. The software used for the stated adaptation survey accessed the database created by the online diary; therefore, data from the pen-and-paper questionnaires had to be entered into the web interface before being used in the interviews.

Based on the relevant day reported by the respondent and chosen for the stated adaptation interview, the modifications were implemented by the interviewers during the interviews. Unlike former studies, the scenarios assigned to the respondents in the household interviews were not aimed at determining the effects of specific policies, but rather formulated as generally as possible, in the following form:

"Imagine your reported trip to [Activity] would take $[y]$ minutes instead of $[x]$. This may result from the location where the activity was conducted relocating or closing, and you needing to choose a different location."

Travel times for the selected trips (and the return trips, if applicable) were progressively increased by 50,100 and 200 per cent, then decreased by 50 per cent, thus creating four scenarios per household. By default, the incurred time losses (or gains) were subtracted from (or added to) the final sojourn at home; thus, for a respondent not reacting to a scenario at all, the total time spent at home would simply increase or decrease by the corresponding amount.

The respondents were asked to state their likely reactions to such a scenario, including the following possibilities:

- choice of a different departure time for certain trips;

- choice of a different travel mode for certain trips;

- changing the order and/or duration of certain activities;

- cancelling certain activities, or adding additional ones;

- combinations of the above.

The day on which the stated adaptation interview was conducted was chosen by the researchers. Ideally, the household members should have conducted a sufficiently large number of activities, so that changes to the schedule would become visible and be substantial enough for the respondents to change their behaviour. Thus, the day with the largest number of conducted activities was used for the interviews. The assignment of scenarios to the household was carried out using heuristics determining which trips were modified. The following rules were applied: 
- If at least one household member is employed (or a student), check for commute trips (that is, trips that have either work or education as a purpose). If such trips are present, change their properties;

- otherwise, if there are children in the household, check whether accompanying trips to or from the children's school(s) are present; if so, vary those trips;

- otherwise, check whether shopping trips are present, and modify one of them accordingly;

- otherwise, modify the longest present leisure trip.

This procedure ensured that priority was given to mandatory (i.e., commute and to a certain extent shopping) trips, which are carried out routinely and for which changing travel conditions represent a larger modification to the scheduling constraints than for leisure trips. The scenarios thus created provided the base for the interactive interviews, where the household members progressively adapted their stated behaviour until attaining a schedule that they were satisfied with. The effects that the scenarios and the stated adaptations had on the respondents' schedules were thus always directly visible to them.

\section{Recruitment Success and Response Rates}

A total of about 2'500 household addresses were acquired from an address dealer, with the requirement that the distribution of household characteristics be representative for the study area (the canton of Zurich). Announcement letters with a brief description of the study were sent to the selected households. A few days after these introductory letters were dispatched, the interviewers called the potential respondents to establish their willingness to participate in the study and provided them with detailed information on the survey process. At the same time, the potential respondents were informed of an incentive of 20.- Swiss Francs given to each participating person. The recruited respondents were assigned the internet or paper questionnaire according to their preference.

In total, phone calls to 2'389 numbers were carried out, 1'344 of which were answered. Members of 340 households agreed to participate in the survey, which corresponds to a recruitment rate of 25.3 per cent. 200 of the recruited households requested a paper questionnaire, while 140 preferred the internet survey. 101 households completed the paper questionnaire, and 57 completed the web survey. Thus, the response rates for the paper and internet questionnaires were 50.5 and 40.7 per cent, respectively. In total, interviews were conducted with 205 persons from 141 participating households (see Table 1).

As Figure 1 shows, response rates are in line with expectations. They match the experiences with comparable studies conducted at ETH Zurich's Institute for Transport Planning and Systems (IVT), for which the ex-ante response burden was determined according to the scheme described in Axhausen, Weis (2009) The methodology assigns weighted scores to question types and sums them up to calculate the overall response burden of a survey. The response rates that are considered here correspond to the COOP4 cooperation rate as defined by the American Association for Public Opinion Research (2011). Response rates decrease with response burden, and the present study fits into its context for surveys with prior recruitment and incentive. Response rates from the online and pen-and-paper questionnaires differ slightly, which is in accordance with former experiences made with the two survey modes (Weis et al., 2010).

\section{Reported Travel Behaviour}

\subsection{General Mobility Figures}

Table 2 shows key mobility figures for the subsamples in comparison with values for the study area taken from the 2005 Swiss National Household Travel Survey (which is called Mikrozensus and abbreviated MZ'05; see Swiss Federal Statistical Office and Swiss Federal Office of Spatial Development 2005). As can be seen, reported weekday mobility is at par with the national sample, 
while trip rates are slightly lower. This may be due to the fact that the Mikrozensus is carried out as a computer assisted telephone interview (CATI), and spans only one day for each respondent. Thus, the reported schedules in the Mikrozensus are checked for inconsistencies by the interviewers. In addition, attrition effects that lead to lower reported mobility as the survey period progresses are expected to be higher in the current study. A similar effect may have caused part of the significant drop in reported mobility for Saturdays and Sundays in the online survey.

\subsection{Modal Split}

The distribution of the modal shares for the reported trips is displayed in the first part of , again along with the corresponding figures from the Mikrozensus. Here, significantly less walk trips are being reported, with public transport having a higher modal share than in the national survey. Two reasons can be brought forward to explain this effect: on the one hand, very short trips (where walking is the preferred mode) tend to be over-represented in the Mikrozensus. On the other hand, the high share of transit pass holders in the sample encourages the use of public transport.

\subsection{Trip Purposes}

The trip purpose distribution for the reported trips and its comparison to the figures from the Mikrozensus are shown in the second part of Table 3. Here, representativeness is reached quite exactly. Leisure accounts for about half of the reported out-of-home activities. Education (and, in the paper questionnaire, work) trips are slightly under-represented, which is due to the slightly skewed age distribution of the sample.

\section{Reactions to Changing Travel Conditions}

As has been mentioned above, the scenarios that are presented to the respondents in the household interviews consist of changing travel times to locations where given activities are conducted. Changes in total travel times resulting from the scenarios cover a broad range, reaching from one and a half hours gained to three hours lost travelling.

When assessing the modified behavioural schemes stated by the respondents, changes in the abovementioned variables defining the structure of the schedule are of main interest: number of activities conducted, trips, and home-to-home tours; departure times; duration of the conducted activities and trips; and duration of the time spent at the home location.

\subsection{Number of Activities}

The relationship between the implied changes in travel times and the number of added or removed out-of-home activities is shown in Figure 2.

The curve serves as a first indicator of how the respondents react to the changes in the scenarios. On the one hand, a large majority of the respondents (about ninety per cent) are reluctant to make significant modifications to their schedules - a large number of them would not let time changes affect their schedule structures. However, as the implied travel time losses become larger, activities are more likely to be cancelled in order to make up for the time losses. In the same vein, significant time gains tend to increase the number of conducted activities. Thus, the respondents' reactions, although weak in this aspect, are consistent with the notion that more favourable travel conditions lead to more mobility and vice-versa (that is, that activities can be considered a normal good, for which reduced costs lead to increasing demand).

\subsection{Departure Time}

A convenient and often (by over two thirds of the respondents) chosen reaction to the changes in travel times is the modification of the departure time for the first trip of the day. Indeed, it appears as the most logical reaction, e.g. for a worker who has to be at the work location at a given time and 
thus adapts their departure time to the changing conditions to accommodate for the required punctuality.

Figure 3 shows that on average, this type of adaptation accounts for the compensation of 30 to 50 per cent of the time gains and losses and thus will likely play a major role in the modelling approach presented in the next chapter.

\subsection{Other Changes}

The analysis has shown that other means to compensate for the time gains and losses are changes in activity and/or trip duration. The former can be accomplished by either cancelling (which, as shown earlier, is not often done) or shortening existing activities. These options were chosen by a total of roughly twenty per cent of the respondents. Changing travel times is done by either changing the mode of transportation for certain trips, under the assumption that an alternative mode will lead to different travel times; or by changing the trip destination, i.e. the location where the according activity is carried out. Around forty per cent of the respondents chose one of the options leading to changed travel times.

\section{Modelling Approach and Results}

The modelling approach that is described here makes the general assumption that time gains or losses can be compensated by the respondents in three different ways (apart from doing nothing, which results in less time spent at home as has been mentioned above), which can be combined in any way to form a new, adapted, schedule:

- adaptation of the departure time from the home location;

- adaptation of the time spent travelling ;

- adaptation of the time spent at out-of-home.

As a consequence, these are the three variables which are the main focus of the modelling approach, which attempts to reproduce the multiple levels of the decision process leading to the adapted schedules. The structure of the modelling approach is shown in Figure 4. The sub-models were chosen to appropriately account for the relevant decisions and are run sequentially when using the model for forecasting. A central input for all model steps is the implied travel time gain or loss, or variables derived therefrom. The sub-models are:

(1) A Multinomial Logit (MNL) model for the decision whether or not to react at all to a given scenario;

(2) a Linear Regression model predicting how much time is compensated (only for those respondents that do react at all);

(3) a Multiple Discrete-Continuous Extreme Value (MDCEV) model, estimating the distribution of the compensated time over the three abovementioned options;

(4) a Cross-Nested Logit (CNL) model, which, based on the resulting changes in travel times and activity durations, predicts whether additional adaptations to the schedule structure will be carried out, i.e. changes to the number of activities and tours or mode choice changes.

When using the model to forecast reactions to a given scenario, the results from one step enter the next step as input variables. The following sub-sections describe the sub-models in detail and provide their results.

7.1. Multinomial Logit (MNL) Model for Predicting the Presence of a Reaction to a Scenario The Multinomial Logit (MNL) model (Train 2003) is the most widespread approach for modelling discrete choices between given alternatives, as is the case for the first sub-model described here. The software BIOGEME (Bierlaire 2003, 2009) was used to estimate the model.

The model results are displayed in Table 4. Linear utility functions were used, comprising all the attributes shown in the table. Separate model parameters were estimated for travel time gains and losses, as the valuation of these attributes was assumed (and has partly been shown in the 
descriptive analysis) to be asymmetric. The "no adaptation" alternative was considered the reference alternative, with utility fixed to zero; the parameters thus represent utility gains that the respective variables contribute to the utility function of the "adaptation" alternative in relation to the "no adaptation" reference. It can be seen that the utility for adapting behaviour (and thus, the choice probability for the alternative) increases with increasing time gains and losses. The age, gender, employment and transit pass ownership variables are dummy-coded, i.e. their parameters represent a utility relative to a reference category. It can be seen for example, that a respondent between 18 and 40 years of age is more likely to react to travel time gains (positive parameter value) than one aged over 65 . The model fit is quite good, with an adjusted $\rho^{2}$ value of 0.410 .

\subsection{Linear Regression Model}

The regression model used for predicting the amount of compensated time for those respondents that reacted to the scenario posed to them, uses the logarithm of the amount of gained or lost travel time as an explanatory variable. Separate parameters for time gains and losses were estimated and are shown in Table 5. It can be seen that time losses are compensated at a higher rate than gains. The model fit is very good, the value for adjusted $R^{2}$ being equal to 0.960 .

7.3. Multiple Discrete-Continuous Extreme Value (MDCEV) Model for the Distribution of Compensated Time

The Multiple Discrete-Continuous Extreme Value (MDCEV), which was introduced by Bhat (2005, 2008) in the context of time use decisions, extends the classical discrete choice model by two components. Firstly, more than one alternative can be chosen; and secondly, it allows predictions of the consumed quantities of the chosen alternatives. Each consumer is assumed to maximise their utility given the available goods. In the approach that is used here, the utility function takes the following form (Hanemann 1978):

$U(\boldsymbol{x})=\sum_{k=1}^{K} \gamma_{k} \psi_{k} \ln \left(\frac{x_{k}}{\gamma_{k}}+1\right)$, where:

$\psi_{k}=$ baseline marginal utility of good $k$

$x_{k}=$ comsumed quantity of good $k$

$\gamma_{k}=$ satiation parameter, limiting the increase of utility with increasing consumption of good $k$

Furthermore, the baseline marginal utility $\psi_{k}$ (i.e., the marginal utility when the consumed quantity of good $k$ equals zero) is parameterised as:

$\psi_{k}=e^{\beta \cdot z_{k}+\varepsilon_{k}}$, where:

$\beta=$ vector of utility parameters

$Z_{k}=$ vector of characteristics of good $k$

$\varepsilon_{k}=$ Gumbel distributed error term

The model estimates the $\beta$ and $\gamma$ parameters using Maximum Likelihood optimisation. The results are shown in Table 6. The adaptation of departure time from home is considered the base alternative, with respect to which the utilities for both other alternatives are computed. As the negative values for the constants imply, the base alternative is inherently preferred to the other alternatives, as choosing it requires the least exertion from the respondents. When time gains or losses increase, so does the propensity of adapting either the travel time or the activity duration. However, the large values for the satiation parameters of these alternatives also suggest that the 
marginal utility decreases more quickly with the consumed amount than that of the departure time adaptation.

As an assessment of model quality, Figure 5 shows the distribution of the departure time adaptations stated by the respondents against that forecast by the model. The forecast distribution matches the actual one quite well; the shares of earlier respectively later departures from the home location are thus correctly reproduced by the model. The same holds for the other time compensation methods (not shown here).

\subsection{Cross-Nested Logit (CNL) Model for Additional Adaptations}

The adaptations which can be chosen by the respondents in addition to, or as a means to attain, the mere time compensations captured by the MDCEV, are changes in mode choice, or adaptations of the number of activities and tours that modify the structure of the reported schedules. Changes in destination choice cannot be directly modelled here, as the survey data lacks the necessary spatial information. They are thus incorporated into the "no further adaptation" alternative. The model approach accounts for similarities between the discrete alternatives by grouping them into nests, where each alternative can be a member of more than one nest. Nests are formed to include alternatives where the number of activities is changed either exclusively or jointly with the number of tours (i.e., removing an activity from a tour that remains in the schedule, or removing a tour altogether). The same hold for tours, where the exclusive removal simply means that a return to the home location is left out, without cancelling an activity (i.e., an activity is shifted to a different tour).

The model results are shown in Table 7. Again, separate parameters were estimated for time gains and losses. The model fit is very high (adjusted $\rho^{2}=0.526$ ). As in the other sub-models, the constants indicate an inherent preference for the alternatives; here, all reactions have a lower base utility than the "no further adaptation" reference alternative. If time gains are compensated by taking more time on the road, this translates into slightly more tours, i.e. the respondents decide to return to their home location more often during the day (as the return home becomes cheaper in terms of generalised costs). On the other hand, time losses compensated by shorter activity durations slightly increase the probability of conducting fewer activities.

As Figure 6 shows, in both the adaptations stated by the respondents and those predicted by the model, the decisions to apply no further adaptations to the schedule or to change the travel mode for a given trip are predominant. The respondents are slightly more willing to cancel activities and tours than they can imagine conducting additional ones when offered more time, which hints to a certain inertia in the stated behaviour, that can however also be observed in reality (e.g. when comparing time use studies from different time periods, as has been done in Weis, Axhausen 2009). The distribution of the chosen alternatives is well reproduced by the model.

\section{Conclusion and Outlook}

Short-term effects on respondents' schedules induced by changing travel conditions were assessed by the means of a stated adaptation survey and the appropriate modelling tools. Reactions to the changes were present, however not as strongly as might have been expected. The reactions are largely limited to changes in departure times from the home location and compensations of travel time losses or gains by changing modes, and very rarely pertain to the actual structure of the reported schedules, i.e. the number of conducted activities and tours. We conclude that, despite the substantial interferences with the existing schedules that were simulated here, travellers are reluctant to change their daily routines and to have disruptions in the transportation system interfere with their planned behaviour. Time gains are often re-invested into travelling, either by changing the mode or by covering larger distances, i.e. changing the locations where activities are carried out. Overall, the findings from Weis, Axhausen (2009) were confirmed, where increasing accessibilities were found to have a positive effect on mobility (here in the longer term), however it was found that the investments that would be necessary to bring about substantial enough 
improvements to travel conditions to trigger those effects would be onerous. To conclude, travellers seem to be very inert in their behaviour as far as it pertains to the trip generation variables that were of interest in the work described here.

\section{Acknowledgements}

The authors gratefully acknowledge the financial support of the SBT-Fonds administered by the Swiss Association of Transport Engineers (SVI 2004/012) and the advice of the steering committee, chaired by Michel Simon and including René Zbinden, Samuel Waldvogel, Stefan Dasen and Helmut Honermann.

Furthermore, we would like to thank Prof. Michel Bierlaire and Dr. Chandra Bhat for making available their software programs for the estimation of discrete and discrete-continuous choice models, respectively.

Christoph Dobler invested a great amount of time and programming skill into the implementation of the survey software, for which he deserves our gratitude.

Last but not least, the student assistants who recruited the survey respondents and carried out the interviews deserve a grateful mention, namely Sarah Brack, Manuela Hess, Rolf Hug, Tina Lohfing, Ana Pajovic, Alessandra Pellegrini and Janira Perrotta. 


\section{References}

Arentze. T.; Hofman, F.; Timmermans, H.J.P. (2004): Predicting Multi-faceted Activity-travel Adjustment Strategies in Response to Possible Congestion Pricing Scenarios Using an Internet-based Stated Adaptation Experiment. In Transport Policy, 11: 31-41.

Axhausen, K.W.; Weis, C. (2010): Predicting Response Rate: A Natural Experiment. In Survey Practice, 3: http://surveypractice.org/2010/04/14/predicting-response-rate/.

Axhausen, K.W.; Zimmermann, A.; Schönfelder, S.; Rindsfüser, G.; Haupt, T. (2002): Observing the Rhythms of Daily Life: A Six-week Travel Diary. In Transportation, 29: 95-124.

Bierlaire, M. (2003): BIOGEME: A Free Package for the Estimation of Discrete Choice Models. Presented at $3^{\text {rd }}$ Swiss Transport Research Conference, Monte Verità, Switzerland, March 2003.

Bierlaire, M. (2009): An Introduction to BIOGEME 1.8. http://biogeme.epfl.ch.

Brown, A.; Mawson, P. (1981): The HATS Technique: An Urban Application in Basildon New Town. Basildon New Town: Basildon New Town Development Corporation.

Doherty, S.T.; Miller, E.J. (2000): A Computerized Household Activity Scheduling Survey. In Transportation, 27: 75-97.

Doherty, S.T.; Lee-Gosselin, M.E.H. (2000): Activity Scheduling Adaptation Experiments under Vehicle Reduction Scenarios. Presented at $9^{\text {th }}$ International Conference on Travel Behaviour Research, Gold Coast, Australia, June 2000.

Doherty, S.T.; Lee-Gosselin, M.E.H.; Burns, K.; Andrey, J.: Household Activity Rescheduling in Response to Automobile Reduction Scenarios. In Transportation Research Record, 1807: 174-182.

Hanemann, W.M. (1978): A Methodological and Empirical Study of the Recreation Benefits from Water Quality Improvement. Ph.D. dissertation, Harvard: Department of Economics, Harvard University.

Jones, P.M. (1979): HATS: A Technique for Investigating Household Decisions. In Environment and Planning A, 11: 59-70.

Jones, P.M. (1980): Experience with Household Activity-Travel Simulator (HATS). In Transportation Research Record, 765: 6-12.

Jones, P.M.; Dix, M.C. (1979): Household Travel in the Woodley-Earley Area: Report of a Pilot Study Using HATS. Oxford: Transport Studies Unit, Oxford University.

Jones, P.M.; Bradley, M.; Ampt, E (1989): Forecasting Household Response to Policy Measures Using Computerised, Activity-based Stated Preference Techniques. In International Association for Travel Behaviour (eds.): Travel Behaviour Research. Aldershot: Avebury, 41-63.

Lee-Gosselin, M.E.H (1989): In-depth Research on Lifestyle and Household Car Use under Future Conditions in Canada. In International Association for Travel Behaviour Research (eds.) Travel Behaviour Research. Aldershot: Avebury, 102-118.

Lee-Gosselin, M.E.H (1990): The Dynamics of Car Use Patterns under Different Scenarios: A Gaming Approach. In Jones, P.M. (ed.) Developments in Dynamic and Activity-Based Approaches to Travel Analysis. Aldershot: Gower, 250-271.

Löchl, M.; Axhausen, K.W.; Schönfelder, S. (2005): Analysing Swiss Longitudinal Travel Data. Presented at $5^{\text {th }}$ Swiss Transport Research Conference, Monte Verità, Switzerland, March 2005.

Louvière, J.J.; Hensher, D.A.; Swait, J. (2000): Stated Choice Methods: Analysis and Applications. Cambridge: Cambridge University Press. 
Martin and Voorhees Associates (1978): Reductions in Rural Bus Services: An Independent Assessment of the HATS Technique. Oxford: Transport Studies Unit, Oxford University.

Phifer, S.P.; Neveu, A.J.; Hartgen, D.T. (1980): Family Reactions to Energy Constraints. In Transportation Research Record, 765: 12-16.

Rose, J.M.; Bliemer, M.C.J.; Hensher, D.A.; Collins, A.C. (2008): Designing Efficient Stated Choice Experiments Involving Respondent Based Reference Alternatives. In Transportation Research B, 42: 395-406.

Swiss Federal Statistical Office and Swiss Federal Office of Spatial Development (2005). Mobilität in der Schweiz: Ergebnisse des Mikrozensus 2005 zum Verkehrsverhalten. Bern: Swiss Federal Statistical Office.

The American Association for Public Opinion Research (2011): Standard Definitions: Final Dispositions of Case Codes and Outcome Rates for Surveys. http://www.aapor.org/Standard_Definitions1.htm. Accessed April 13, 2011.

Train, K.A. (2003): Discrete Choice Models with Simulation. Cambridge: Cambridge University Press.

Van Knippenberg-den Brinker C.; Clarke, M. (1984): Taking Account of when Passengers Want to Travel. In Traffic Engineering and Control, 25: 602-605.

Van Knippenberg-den Brinker, C.; Lameijer, I. (1985). Simulation Studies as a Tool for Determining Public Transport Services in Rural Areas. In Jansen, G.R.M.; Nijkamp, P.; Ruijgro, C.J. (eds.) Transportation and Mobility in an Era of Transition. Amsterdam: Elsevier, 323-333.

Vrtic, M.; Axhausen, K.W. (2003): The Impact of Tilting Trains in Switzerland: A Route Choice Model of Regional- and Long Distance Public Transport Trips. Presented at $83^{\text {rd }}$ Annual Meeting of the Transportation Research Board, Washington, D.C., U.S.A., January 2003.

Vrtic, M.; Schüssler, N.; Erath, A.; Axhausen, K.W. (2010): The Impacts of Road Pricing on Route and Mode Choice Behaviour. In Journal of Choice Modelling, 3: 109-126.

Weis, C. (2009): Structural Equations Modeling of Travel Behaviour Dynamics Using a Pseudo Panel Approach. Presented at $12^{\text {th }}$ International Conference on Travel Behaviour Research, Jaipur, India, December 2009.

Weis, C.; Axhausen, K.W. (2009): Induced Travel Demand: Evidence from a Pseudo Panel Data Based Structural Equations Model. In Research in Transportation Economics, 25: 8-18.

Weis, C; Axhausen, K.W., Dobler, C (2010): Stated Adaptation Survey of Household Activity Scheduling. Presented at $12^{\text {th }}$ World Conference on Transportation Research, Lisbon, Portugal, July 2010.

Weis, C.; Axhausen, K.W.; Frei, A.; Haupt, T.; Fell, B. (2008): A Comparative Study of Web- and Paperbased Travel Behaviour Surveys. Presented at European Transport Conference, Noordwijkerhout, Netherlands, October 2008.

Weis, C.; Axhausen, K.W.; Schlich, R; Zbinden, R. (2010): Models of Mode Choice and Mobility Tool Ownership Beyond 2008 Fuel Prices. In Transportation Research Record, 2157: 86-94. 
11. Figure Titles (the figures are submitted as separate files)

Figure 1 Response rates in the context of comparable studies

Figure 2 Changes in number of out-of-home activities induced by changing travel times

Figure 3 Changes in departure times induced by changing travel times

Figure $4 \quad$ Structure of the proposed modeling approach

Figure 5 Prediction quality of MDCEV: distribution of departure time adaptations

Figure 6 Prediction quality of CNL: distribution of reactions 


\section{Tables}

Table 1 Key Recruitment and Response Figures

\begin{tabular}{|c|c|c|c|}
\hline & Total & Online & Paper \\
\hline Numbers dialed & 2 '389 & & \\
\hline Reached & $1^{\prime} 344$ & & \\
\hline Recruited & 340 & 140 & 200 \\
\hline Recruitment rate [\%] & 25.3 & & \\
\hline Sent & 640 & 140 & 200 \\
\hline Completed diary (households) & 158 & 57 & 101 \\
\hline Completed diary (persons) & 226 & 96 & 130 \\
\hline Response rate [\%] & 46.5 & 40.7 & 50.5 \\
\hline Interviews conducted (households) & 141 & & \\
\hline Interviews conducted (persons) & 205 & & \\
\hline
\end{tabular}


Table 2 Key Mobility Figures

\begin{tabular}{|c|c|c|c|}
\hline Mobility figures & Sample: online & Sample: paper & MZ'05 \\
\hline Working days (Monday - Friday) & $N^{*}=293$ & $N^{*}=394$ & \\
\hline Share of mobile persons [\%] & 91.8 & 91.6 & 91.0 \\
\hline Average number of trips (all persons) & 3.57 & 3.14 & 3.67 \\
\hline Average number of trips (mobiles only) & 3.89 & 3.42 & 4.03 \\
\hline Saturday & $\mathrm{N}=65$ & $\mathrm{~N}=42$ & \\
\hline Share of mobile persons [\%] & 70.8 & 92.9 & 89.4 \\
\hline Average number of trips (all persons) & 3.09 & 3.21 & 3.26 \\
\hline Average number of trips (mobiles only) & 4.37 & 3.46 & 3.64 \\
\hline Sunday & $\mathrm{N}=48$ & $N=31$ & \\
\hline Share of mobile persons [\%] & 66.7 & 80.6 & 79.3 \\
\hline Average number of trips (all persons) & 2.17 & 2.26 & 2.11 \\
\hline Average number of trips (mobiles only) & 3.25 & 2.80 & 2.66 \\
\hline
\end{tabular}

${ }^{*} \mathrm{~N}$ is the number of person days in the sample. 
Table 3 Modal Share and Trip Purpose Distributions (in Per cent)

\begin{tabular}{lrrr}
\hline Main mode & Sample: online & Sample: paper & MZ'05 \\
\hline Walk & 18.6 & 21.2 & 28.4 \\
Bicycle & 9.5 & 5.7 & 7.0 \\
Car or motorcycle & 52.5 & 46.0 & 51.5 \\
Public transport & 16.4 & 25.1 & 11.9 \\
Other & 3.0 & 2.0 & 1.2 \\
\hline Trip purpose & Sample: online & Sample: paper & MZ'05 \\
\hline Education & 0.9 & 0.5 & 1.1 \\
Work & 19.2 & 12.1 & 16.0 \\
Shopping / errand & 13.2 & 15.0 & 16.0 \\
Business & 2.7 & 0.7 & 2.1 \\
Leisure & 26.7 & 28.0 & 25.7 \\
Return home & 37.3 & 43.7 & 39.1 \\
\hline
\end{tabular}


Table 4 Model results: MNL

\begin{tabular}{|c|c|c|c|}
\hline Alternative & Parameter & Value & t statistic \\
\hline \multirow{21}{*}{ Adaptation } & For travel time gains: & & \\
\hline & Constant & 2.490 & 1.80 \\
\hline & Logarithm of amount of gained time & 1.330 & 4.18 \\
\hline & Logarithm of travel time reported in diary & -0.805 & -2.36 \\
\hline & Age: between 18 and 40 years & -1.340 & -2.90 \\
\hline & Age: between 40 and 65 years (reference category) & - & - \\
\hline & Age: over 65 years & -1.930 & -3.22 \\
\hline & Male respondent & -0.284 & -1.19 \\
\hline & Female respondent (reference category) & - & - \\
\hline & Respondent is employed & -1.030 & -2.55 \\
\hline & Transit pass ownerhsip & -0.755 & -1.63 \\
\hline & For travel time losses: & & \\
\hline & Constant & -0.138 & -0.17 \\
\hline & Logarithm of amount of lost time & 1.290 & 5.80 \\
\hline & Number of tours reported in diary & -0.877 & -4.82 \\
\hline & Age: between 18 and 40 years & 0.267 & 0.66 \\
\hline & Age: between 40 and 65 years (reference category) & - & \\
\hline & Age: over 65 years & -1.900 & -3.90 \\
\hline & Male respondent & -0.284 & -1.19 \\
\hline & Female respondent (reference category) & - & \\
\hline & Respondent is employed & -1.030 & -2.55 \\
\hline \multirow[t]{2}{*}{ No adaptation } & None (reference alternative, utility $=0$ ) & - & \\
\hline & & Adjusted & $=0.410$ \\
\hline
\end{tabular}

Values printed in italic are statistically significant at the 5 per cent level $(\mathrm{t}>1.96)$. 
Table 5 Model results: Linear Regression

\begin{tabular}{llcr}
\hline Parameter & & Value & t statistic \\
\hline For travel time gains: & & 0.719 & 2.40 \\
& Constant & 0.656 & 7.62 \\
& Logarithm of amount of gained time & & \\
For travel time losses: & & -0.175 & -0.84 \\
& Constant & 0.974 & 18.50 \\
& Logarithm of amount of lost time & Adjusted $R^{2}=0.960$ \\
\hline
\end{tabular}

Values printed in italic are statistically significant at the 5 per cent level $(t>1.96)$. 
Table 6 Model results: MDCEV

\begin{tabular}{|c|c|c|c|c|}
\hline Case & Reaction & Parameter & Value & t statistic \\
\hline \multirow{8}{*}{ Time gain } & Later departure & Satiation parameter $(\gamma)$ & 0.139 & 3.15 \\
\hline & More travel time & Constant & -0.500 & -0.88 \\
\hline & & Amount of compensated time & 0.386 & 0.60 \\
\hline & & Satiation parameter $(\gamma)$ & 1.119 & 1.16 \\
\hline & Longer activities & Constant & -3.629 & -3.29 \\
\hline & & Amount of compensated time & 3.004 & 4.20 \\
\hline & & Reported time spent at home & 0.726 & 0.69 \\
\hline & & Satiation parameter $(\gamma)$ & 0.359 & 1.76 \\
\hline \multirow{9}{*}{ Time loss } & Earlier departure & Satiation parameter $(\not)$ & 0.266 & 5.59 \\
\hline & Less travel time & Constant & -1.166 & -7.80 \\
\hline & & Amount of compensated time & 0.691 & 4.68 \\
\hline & & Satiation parameter $(\gamma)$ & 1.324 & 3.14 \\
\hline & Shorter activities & Constant & -2.967 & -9.41 \\
\hline & & Amount of compensated time & 1.120 & 6.93 \\
\hline & & Reported duration of out-of-home activities & 1.162 & 2.03 \\
\hline & & Satiation parameter $(\gamma)$ & 0.393 & 3.74 \\
\hline & & & \multicolumn{2}{|r|}{$\rho^{2}=0.234$} \\
\hline
\end{tabular}

Values printed in italic are statistically significant at the 5 per cent level $(\mathrm{t}>1.96)$. 
Table 7 Model results: CNL

\begin{tabular}{llrr}
\hline Adaptation & Parameter & Value & t statistic \\
\hline No further adaptation & None (reference alternative) & - & - \\
\hline More activities & Constant & -2.670 & -5.17 \\
\hline More tours & Constant & -35.600 & 0.00 \\
& Amount of additional travel time & 0.161 & 4.47 \\
\hline More activities and tours & Constant & -5.990 & -3.63 \\
\hline Less activities & Constant & -3.610 & -7.84 \\
& Amount of compensated activity duration & 0.005 & 2.78 \\
& Number of reported activities & 0.417 & 3.44 \\
\hline Less tours & Constant & -8.240 & -8.07 \\
& Amount of compensated travel time & 0.098 & 8.78 \\
& Number of reported tours & 1.530 & 4.30 \\
\hline Less activities and tours & Constant & -9.390 & -8.64 \\
\hline Mode choice & Dummy for travel time gain & -0.967 & -3.90 \\
& Dummy for travel time loss & -1.430 & -8.28 \\
& Amount of additional travel time & 0.108 & 4.92 \\
& Amount of compensated travel time & 0.081 & 8.13 \\
\hline
\end{tabular}

Values printed in italic are statistically significant at the 5 per cent level $(\mathrm{t}>1.96)$. 